\title{
Weekly paclitaxel as second-line chemotherapy for advanced or recurrent gastric cancer
}

\author{
Shuichi Hironaka, Sadamoto Zenda, Narikazu Boku, Akira Fukutomi, Takayuki Yoshino, \\ and Yusuke ONOZAWA \\ Division of Gastrointestinal Oncology, Shizuoka Cancer Center, 1007 Shimonagakubo, Nagaizumi-cho, Shizuoka 411-8777, Japan
}

\begin{abstract}
Background. Paclitaxel scheduled every 3 weeks has shown a response rate of $\sim 20 \%$ for gastric cancer, with modest hematological toxicity. Weekly administration of paclitaxel in patients with breast or ovarian cancer has shown equivalent efficacy and milder toxicity compared with an every-3 week schedule. We investigated, retrospectively, the antitumor effects and toxicity profiles of weekly paclitaxel for patients with metastatic or recurrent gastric cancer in clinical practice.

Methods. In 38 patients who had metastatic or recurrent histologically confirmed gastric cancer and a history of one prior chemotherapy regimen, other than paclitaxel or docetaxel, paclitaxel $\left(80 \mathrm{mg} / \mathrm{m}^{2}\right)$ was administered weekly, three times every 4 weeks, with short-term premedication.

Results. All 38 patients had had prior chemotherapy that included 5-fluorouracil, the fluoropyrimidine anticancer drug $\mathbf{S - 1}$, or cisplatin. The median number of courses in the present regimen was 6 (range, $1-44+$ ). Dose intensity was $55 \mathrm{mg} / \mathrm{m}^{2}$ per week, corresponding to $92 \%$ of the planned dose $\left(60 \mathrm{mg} / \mathrm{m}^{2}\right.$ per week). The overall response rate was $24 \%(6 / 25)$ in measurable lesions, and pleural effusion and ascites disappeared in 2 of 7 patients $(29 \%)$ and in 3 of 21 patients (14\%), respectively. Median survival time was 151 days from the commencement of this treatment, with a median follow-up period of 260 days. Grade 3 or 4 leukopenia and neutropenia were observed in $11(29 \%)$ and $12(32 \%)$ patients, respectively. Seven patients $(\mathbf{1 8 \%})$ died within 30 days of the last administration of paclitaxel.

Conclusion. Weekly paclitaxel seems to be active as secondline chemotherapy against metastatic and recurrent gastric cancer. Further study is needed to confirm the efficacy and safety of weekly paclitaxel.
\end{abstract}

Key words Gastric cancer · Weekly paclitaxel · Second-line chemotherapy

Offprint requests to: $\mathrm{S}$. Hironaka

Received: August 12, 2005 / Accepted: October 24, 2005
Introduction

Gastric cancer remains as one of the major causes of death from cancer worldwide. Despite a markedly improved survival trend through early detection and curative surgery, approximately 50000 deaths from gastric cancer occurred in Japan in 1997 [1]. Although patients with metastatic and recurrent gastric cancer still have a poor prognosis, no standard chemotherapy regimen has been established, even as the first-line.

Paclitaxel is an antitumor agent active against various kinds of malignancies. Because paclitaxel is known to be a cell-cycle-specific agent [2,3], basic research has suggested that prolongation of exposure might enhance its cytotoxic effects. In a phase I study of weekly paclitaxel, a regimen of $80 \mathrm{mg} / \mathrm{m}^{2}$ in a 3-weeks-on and 1 week-off schedule was recommended [4]. In this phase I study, a weekly paclitaxel regimen (1-h infusion) produced objective tumor regression in patients previously treated with paclitaxel on a once-every-3-weeks schedule. Recently, successful results have been achieved using a regimen of weekly paclitaxel in patients with breast cancer and ovarian cancer. Hematological toxicity caused by a weekly 3 -h infusion schedule has been reported to be milder, with equivalent activity, compared with a schedule of one 24 -h infusion every 3 weeks [5].

Paclitaxel is recognized as one of the active cytotoxic agents for gastric cancer [6-9]. A weekly paclitaxel regimen has become popular in Japan, mainly as secondline chemotherapy, because of its milder hematological toxicity compared with a once every 3 weeks schedule of paclitaxel. However, only a few trials of weekly paclitaxel in patients with gastric cancer have been reported $[10,11]$. In the present retrospective study, we investigated the potential and safety of this more dosedense weekly paclitaxel regimen in patients with pretreated gastric cancer. 


\section{Patients and methods}

\section{Patients}

The subjects of this study consisted of 38 patients with metastatic or recurrent gastric cancer treated weekly with paclitaxel between September 2002 and September 2004 at the Shizuoka Cancer Center, Shizuoka, Japan. The recruitment criteria were as follows: (1) histologically proven adenocarcinoma of the stomach; (2) history of one prior chemotherapy regimen not involving paclitaxel or docetaxel; (3) age, 75 years or less; (4) performance status of 2 or less on the Eastern Cooperative Oncology Group scale; (5) adequate bone marrow, hepatic, and renal functions; (6) no other serious disease; (7) and oral or written informed consent given before the commencement of treatment.

\section{Treatment methods}

The treatment schedule comprised an intravenous infusion of paclitaxel at $80 \mathrm{mg} / \mathrm{m}^{2}$ in $250 \mathrm{ml}$ normal saline over $1 \mathrm{~h}$, repeated weekly three times for 4 weeks. Short-term premedication for paclitaxel-associated hypersensitivity reactions was used: dexamethasone, $8 \mathrm{mg}$; diphenhydramine, $50 \mathrm{mg}$; ranitidine, $50 \mathrm{mg}$; and granisetron, $3 \mathrm{mg}$ were administered $30 \mathrm{~min}$ before the paclitaxel treatment. This treatment was repeated until disease progression or prohibitive toxicity, usually on an outpatient basis. In the event of serious hematological toxicity, treatment was suspended until recovery. If grade 4 hematological or grade 3 or 4 nonhematological toxicity occurred, the dose of paclitaxel was reduced to $60 \mathrm{mg} / \mathrm{m}^{2}$

\section{Response and toxicity assessments}

Tumor measurements for response assessment in patients with primary lesions were made every 1 to 2 months by computed tomography (CT) and endoscopy. Objective responses in measurable metastatic lesions were evaluated according to the response evaluation criteria for solid tumors [12]. Survival time was calculated from the date of the commencement of paclitaxel treatment to the date of death or the last confirmation of survival. Symptomatic toxicity and laboratory data were monitored every week at the outpatient clinic. Toxicity was evaluated according to the National Cancer Institute common toxicity criteria (version 2).

\section{Results}

\section{Patient population}

Of 51 patients with advanced or recurrent gastric cancer treated with weekly paclitaxel as second-line chemo- therapy, 38 patients fulfilled the recruitment criteria, and were included in this study. The 13 excluded patients had severe medical complications: 4 patients were aged 76 years or more, and 9 were performance status 3 or more.

Patient characteristics are presented in Table 1. Most (63\%) were male, and the median age was 63 years. Twenty seven $(71 \%)$ had a performance status of 0 or 1 . All patients had had prior fluorouracil-based chemotherapy as first-line chemotherapy. Seven patients had pleural effusion and 21 had ascites. The number of metastatic organs (including liver, lymph node [LN], peritoneum, lung and bone), was one organ in 15 patients, two organs in 14 patients, and three organs or more in 9 patients.

\section{Dose intensity}

The total number of administrations of paclitaxel was 364. The median number of courses per patient was 6 (range, 1-44+). Dose intensity was calculated as $55 \mathrm{mg} / \mathrm{m}^{2}$ per week, which corresponded to $92 \%$ of the planned dose. This treatment was stopped in 35 patients, because of disease progression in 31 patients,

Table 1. Patient characteristics

\begin{tabular}{|c|c|}
\hline No. of patients & 38 \\
\hline \multicolumn{2}{|l|}{ Sex } \\
\hline Male & 24 \\
\hline Female & 14 \\
\hline \multicolumn{2}{|l|}{ Age (years) } \\
\hline Median & 63 \\
\hline Range & $51-73$ \\
\hline \multicolumn{2}{|l|}{ Performance status } \\
\hline 0 & 12 \\
\hline 1 & 15 \\
\hline 2 & 11 \\
\hline \multicolumn{2}{|c|}{ Prior chemotherapy } \\
\hline S-1 & 29 \\
\hline $\mathrm{MTX}+5-\mathrm{FU}$ & 4 \\
\hline $\mathrm{S}-1+\mathrm{CDDP}$ & 2 \\
\hline $5-\mathrm{FU}$ & 1 \\
\hline $5-\mathrm{FU}+\mathrm{CDDP}$ & 1 \\
\hline UFT & 1 \\
\hline \multicolumn{2}{|l|}{ Histology } \\
\hline Intestinal & 13 \\
\hline Diffuse & 21 \\
\hline Unknown & 4 \\
\hline \multicolumn{2}{|l|}{ Sites of metastasis ${ }^{\mathrm{a}}$} \\
\hline Liver & 10 \\
\hline Lymph node & 21 \\
\hline Peritoneum & 29 \\
\hline Lung & 2 \\
\hline Bone & 4 \\
\hline Pleural effusion & 7 \\
\hline Ascites & 21 \\
\hline
\end{tabular}

${ }^{a}$ Some patients had metastases at multiple sites 
Table 2. Toxicity

\begin{tabular}{lccccc}
\hline & Grade 1 & Grade 2 & Grade 3 & Grade 4 & $\begin{array}{c}\text { Percentage } \\
\geq \text { grade 3 }\end{array}$ \\
\hline Leukocytes & 7 & 5 & 9 & 2 & 29 \\
Neutrophils & 4 & 6 & 6 & 6 & 32 \\
Platelets & 2 & 2 & 3 & 0 & 8 \\
Nausea & 6 & 2 & 1 & - & 3 \\
Vomiting & 4 & 0 & 0 & 0 & 0 \\
Anorexia & 7 & 8 & 1 & 0 & 3 \\
Diarrhea & 4 & 1 & 1 & 0 & 3 \\
Neuropathy-motor & 0 & 0 & 1 & 0 & 3 \\
Neuropathy-sensory & 0 & 9 & 1 & 0 & 3 \\
Edema & 3 & 1 & 1 & 0 & 3 \\
Allergic reactions & 3 & 0 & 0 & 0 & 0 \\
\hline
\end{tabular}

infection in 1 , neuropathy in 1 , refusal of further treatment in 1, and non-cancer death related in 1 patient.

\section{Toxicity}

Toxicity data are presented in Table 2 . Of hematological toxicities, 11 patients $(29 \%)$ experienced leukopenia of grade 3 or 4 and 12 (32\%) had neutropenia of grade 3 or 4 . Of nonhematological toxicities, 1 patient $(3 \%)$ had grade 3 nausea and anorexia. Severe neuropathy was seen in 1 patient (3\%) and no allergic reaction was seen in any patient. Seven patients $(18 \%)$ died within 30 days of the last administration of paclitaxel. The reasons for these early deaths were disease progression in 3 patients; death of other causes (acute myocardial infarction in 1 and heart failure in 1); perforation of the esophagus in 1 (due to an inserted expandable metallic stent for esophageal stenosis caused by mediastinal lymph-node metastasis); and sepsis with grade 4 neutropenia in 1.

\section{Responses and survival}

Twenty-five of the 38 patients were assessable for response (13 patients did not have measurable disease). Of these 25 patients, $6(24 \%)$ experienced a partial response (Table 3 ). The details of the responders are shown in Table 4. Pleural effusion disappeared in 2 of 7 patients (29\%) and decreased in 1 of 7 patients (14\%) after treatment with paclitaxel. Ascites disappeared in 3 of 21 patients $(14 \%)$ and decreased in 2 of 21 patients $(10 \%)$. The median follow-up period was 260 days. Survival data were updated in February 2005. The median survival time was 151 days after the initiation of weekly paclitaxel therapy (Fig. 1). The median time to progression was 64 days (Fig. 2). Twenty-one patients (55\%) had no further chemotherapy after disease progression following paclitaxel therapy. Nine patients had
Table 3. Response

\begin{tabular}{cccccc}
\hline$n$ & PR & SD & PD & NE & RR \\
\hline 25 & 6 & 4 & 14 & 1 & $24 \%$
\end{tabular}

$\mathrm{PR}$, partial response; SD, stable disease; $\mathrm{PD}$, progressive disease; NE, not evaluable; $R R$, response rate

irinotecan-containing regimens, 2 had a 5-fluorouracil (5-FU)-based regimen, 1 had intraperitoneal administration of cisplatin (CDDP), and 1 had palliative radiation therapy at the primary site.

\section{Discussion}

Recently, weekly paclitaxel has been commonly used in second-line or higher chemotherapy. In the present retrospective study, all 38 patients had a history of prior chemotherapy at our institution. Moreover, 9 patients $(24 \%)$ had three involved metastatic sites, and 4 (11\%) had bone metastases. Seven patients had pleural effusion and 21 had ascites. To clarify the activity and toxicity of paclitaxel as second-line chemotherapy in a clinical practice setting, the recruitment criteria for this study allowed patients to have pleural effusion and/or ascites.

We found weekly paclitaxel therapy to be well tolerated by most patients, considering the dose intensity used and its toxicity profile. Previous reports showed that grade 3 or 4 neutropenia occurred in $37 \%$, and grade 4 neutropenia in $67 \%$ of patients treated with paclitaxel on an every-3-weeks regimen [7,9]. In our study, $29 \%$ and $32 \%$ of patients had severe leukopenia and severe neutropenia, respectively. On the basis of these results, a weekly regimen of paclitaxel seems to be less toxic than an every-3-weeks regimen in terms of 
Table 4. Details of responders treated with weekly paclitaxel

\begin{tabular}{lcclcrr}
\hline $\begin{array}{l}\text { Patient } \\
\text { no. }\end{array}$ & $\begin{array}{c}\text { Age } \\
\text { (years) }\end{array}$ & Sex & \multicolumn{1}{c}{ Metastatic site } & $\begin{array}{c}\text { Reduction } \\
\text { ratio }\end{array}$ & $\begin{array}{c}\text { Total number of } \\
\text { administrations }\end{array}$ & $\begin{array}{c}\text { Response duration } \\
\text { (days) }\end{array}$ \\
\hline 1 & 68 & M & Abdominal wall & $61 \%$ & 44 & 413 \\
2 & 57 & F & LN, peritoneum & $32 \%$ & 6 & 41 \\
3 & 65 & F & LN, liver & $37 \%$ & 5 & 50 \\
4 & 72 & M & Liver, LN, peritoneum & $36 \%$ & 13 & 119 \\
5 & 71 & M & Liver, LN, lung & $35 \%$ & 11 & 328 \\
6 & 66 & M & LN, abdominal wall, & $70 \%$ & & \\
& & peritoneum & &
\end{tabular}

LN, lymph node

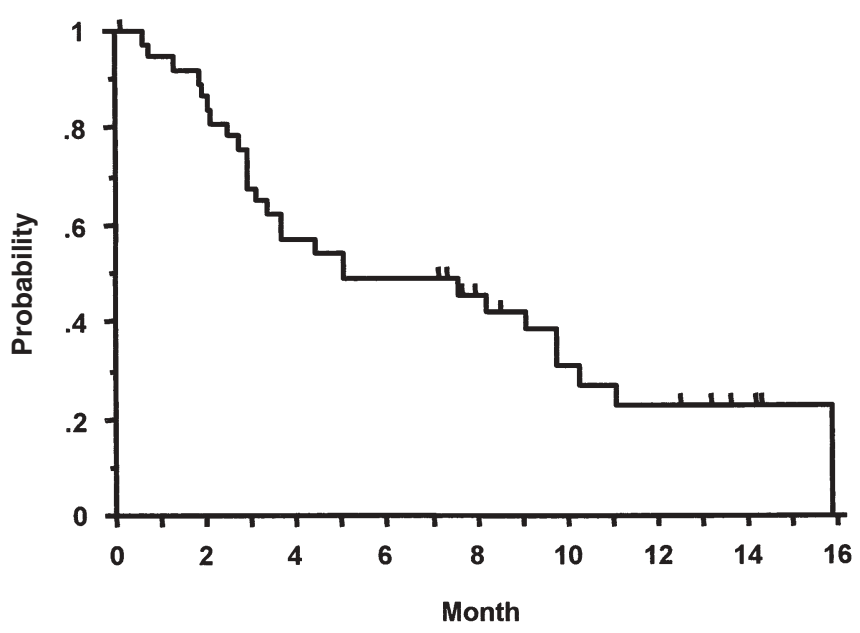

Fig. 1. Kaplan-Meier analysis of overall survival. Median overall survival time was 151 days

hematological toxicity. Furthermore, nonhematological toxicities were generally mild.

Seven patients died within 30 days of the last administration of paclitaxel. The causes of the deaths in our study were disease progression in three patients, other medical diseases in two patients, complications due to a metallic stent in one, and treatment-related sepsis in one. These patients had had a severe medical condition or poor oral intake and poor performance status at the last administration of paclitaxel. Therefore, we have to take care regarding the patient's condition and consider cautiously the indications for the administration of paclitaxel.

With weekly paclitaxel therapy, we observed a response rate of $24 \%$ in 25 patients with measurable metastatic lesions. Disease stabilization was observed in $40 \%$ (10/25). Ascites and pleural effusion decreased or disappeared in $24 \%(5 / 21)$ and $43 \%$ (3/7), respectively. Direct comparison of response rates from one trial to another is inherently difficult, given that studies often differ with respect to entry criteria and population char-

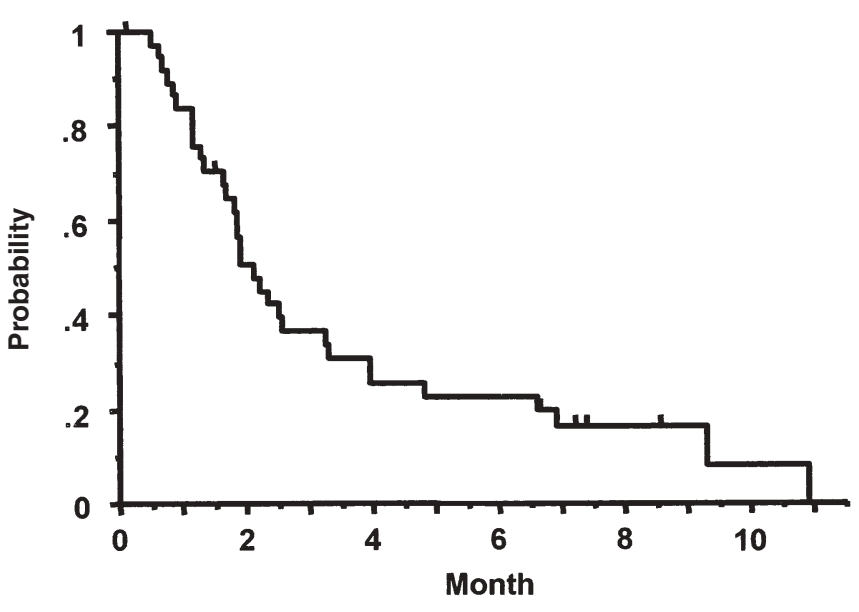

Fig. 2. Kaplan-Meier analysis of time to progression. Median time to progression was 64 days

acteristics. Nevertheless, overall response rates of $8 \%-$ $27 \%$ have been reported in other trials of single-agent paclitaxel administered for gastric cancer at doses of $210 \mathrm{mg} / \mathrm{m}^{2}$ by 3 -h infusion every 3 weeks for gastric cancer [6-9]. Therefore, our response results are within the range observed in other trials, of paclitaxel given every 3 weeks.

On the basis of previously reported data, the median survival time for metastatic or recurrent gastric cancer is about 7 to 9 months [13-17] with first-line chemotherapy. In the present retrospective study, the median overall survival time after the administration of paclitaxel was about 5 months. These data are the same as the previously reported data [10] for weekly paclitaxel. Our results suggest that weekly paclitaxel may have similar activity to paclitaxel given on a 3-week schedule for patients with metastatic or recurrent gastric cancer after prior therapy.

In conclusion, weekly paclitaxel as second-line chemotherapy was tolerated and demonstrated activity against metastatic and recurrent gastric cancer. How- 
ever, its administration in practice must be decided with caution in patients in poor condition. The Japan Clinical Oncology Group (JCOG) is now conducting a randomized phase II trial of weekly paclitaxel versus best available 5-FU for second-line chemotherapy for gastric cancer with peritoneal dissemination.

\section{References}

1. Health and Welfare Statistics Association (1999) The movement of population. J Health Welfare Stat 46:41-72.

2. Rowinsky EK, Donehower RC, Jones RJ, Tucker RW. Microtubule changes and cytotoxicity in leukemic cell lines treated with taxol. Cancer Res 1998;48:4093-100.

3. Lopes NM, Adams EG, Pitts TW, Bhuyan BK. Cell kill kinetics and cell cycle effects of taxol on human and hamster ovarian cell lines. Cancer Chemother Pharmacol 1993;32:235-42.

4. Fennelly D, Aghajanian C, Shapiro F, O'Flaherty C, McKenzie $\mathrm{M}$, O'Connor C, et al. Phase I and pharmacologic study of paclitaxel administered weekly in patients with relapsed ovarian cancer. J Clin Oncol 1997;15:187-92.

5. Eisenhauer EA, ten Bokkel Huinink WW, Swenerton KD, Gianni L, Myles J, van der Burg ME, et al. European-Canadian randomized trial of paclitaxel in relapsed ovarian cancer: highdose versus low-dose and long versus short infusion. J Clin Oncol 1994;12:2654-66.

6. Ajani JA, Fairweather J, Dumas P, Patt YZ, Pazdur R, Mansfield PF. Phase II study of Taxol in patients with advanced gastric carcinoma. Cancer J Sci Am 1998;4:269-74.

7. Yamada Y, Shirao K, Ohtsu A, Boku N, Hyodo I, Saitoh H, et al. Phase II trial of paclitaxel by 3-h infusion for advanced gastric cancer with short premedication for prophylaxis against paclitaxel-associated hypersensitivity reactions. Ann Oncol 2001; 12:1133-7.

8. Garcia AA, Leichman CG, Lenz HJ, Baranda J, Lujan R, Casagrande Y, et al. Phase II trial of outpatient schedule of paclitaxel in patients with previously untreated metastatic, measurable adenocarcinoma of the stomach. Jpn J Clin Oncol 2001;31:275-8.

9. Ohtsu A, Boku N, Tamura F, Muro K, Shimada Y, Saigenji K, et al. An early phase II study of a 3-h infusion of paclitaxel for advanced gastric cancer. Am J Clin Oncol 1998;21:416-9.

10. Arai T, Hamaguchi T, Shirao K, Shimada Y, Yamada Y, Muro K, et al. Weekly paclitaxel in patients with heavily treated advanced gastric cancer. Proc Am Soc Clin Oncol 2003;22:321.

11. Cho H, Shotsu A, Konishi K, Kanari M, Tsuburaya A, Kobayashi $\mathrm{O}$, et al. Weekly paclitaxel for the second-line treatment of recurrent and advanced cancer (RAGC). Proc Am Soc Clin Oncol 2002;21:357.

12. Gehan EA, Tefft MC. Will there be resistance to the RECIST (Response evaluation criteria in solid tumors)? J Natl Cancer Inst 2000;92:179-81.

13. Ohtsu A, Shimada Y, Shirao K, Boku N, Hyodo I, Saito H, et al. Randomized phase III trial of fluorouracil alone versus fluorouracil plus cisplatin versus uracil and tegafur plus mitomycin in patients with unresectable, advanced gastric cancer: The Japan Clinical Oncology Group Study (JCOG9205). J Clin Oncol 2003;21:54-9.

14. Boku N, Ohtsu A, Shimada Y, Shirao K, Seki S, Saito H, et al. Phase II study of a combination of irinotecan and cisplatin against metastatic gastric cancer. J Clin Oncol 1999;17:319-23.

15. Sakata Y, Ohtsu A, Horikoshi N, Sugimachi K, Mitachi Y, Taguchi T. Late phase II study of novel oral fluoropyrimidine anticancer drug S-1 ( $1 \mathrm{M}$ tegafur- $0.4 \mathrm{M}$ gimestat- $1 \mathrm{M}$ otastat potassium) in advanced gastric cancer patients. Eur J Cancer 1998;34:1715-20.

16. Koizumi W, Kurihara M, Nakano S, Hasegawa K. Phase II study of S-1, a novel oral derivative of 5-fluorouracil, in advanced gastric cancer. For the S-1 Cooperative Gastric Cancer Study Group. Oncology 2000;58:191-7.

17. Sugimachi K, Maehara Y, Horikoshi N, Shimada Y, Sakata Y, Mitachi Y, et al. An early phase II study of oral S-1, a newly developed 5-fluorouracil derivative for advanced and recurrent gastrointestinal cancers. The S-1 Gastrointestinal Cancer Study Group. Oncology 1999;57:202-10. 